\title{
O scratch na sala de aula: o uso da programação com vista à resolução de problemas
}

\author{
El scratch en la sala de clase: el uso de la programación para la \\ resolución de problemas
}
The scratch in the classroom: using the programming to view troubleshooting

\author{
Richard Nunes Machado1 \\ Vanda Leci Bueno Gauterio² \\ Mariana Obiedo Piñeiro ${ }^{3}$ \\ Renata Truquijo Crizel ${ }^{4}$
}

\begin{abstract}
Resumo
Este trabalho tem o objetivo de refletir sobre como utilizar as Tecnologias Digitais na sala de aula para potencializar o ensinar e o aprender. Um estudo que movimentou o grupo os inquietando sobre qual seria o papel do professor diante desta realidade. Assim, foi realizado uma análise qualitativa de uma oficina em sala de aula, destacando a sua usabilidade técnica e pedagógica do software Scratch. A pesquisa, embasada na perspectiva teórica de Moran (2013), Papert (2007), Prensky (2013), Lorenzato (2012) e Pimenta (1997), foi realizada a partir da oficina intitulada "O Scratch potencializando o aprender", desenvolvida pelos integrantes do Laboratório de Ensino de Matemática e Física (LEMAFI), da Universidade Federal do Rio Grande - FURG, oferecida para alunos do segundo semestre de Matemática Licenciatura desta universidade. O estudo mostrou que o uso do Scratch no ensino da Matemática contribui para além da aprendizagem dos conceitos, com uma programação de forma simples os estudantes perpassam por situações diferenciadas, na introdução de situações abertas e sugestivas para que busquem suas próprias respostas, a partir de seus conhecimentos prévios e os (re)elaborando, atividades que eleva a autoestima, os torna criativos e reflexivos e desenvolve habilidades para o trabalho em equipe, com respeito ao outro.
\end{abstract}

Palavras-chave: Scratch, Oficina Pedagógica, Matemática, Programação, Situação problema.

\section{Resumen}

Este trabajo tiene el objetivo de reflexionar sobre cómo utilizar las Tecnologías Digitales en el aula para potenciar el enseñar y el aprender. Un estudio que movió al grupo inquietando sobre cuál sería el papel del profesor frente a esta realidad. Así, se realizó un análisis cualitativo de un taller en el aula, destacando su usabilidad técnica y pedagógica del software Scratch. La investigación, basada en la perspectiva teórica de Moran (2013), Papert (2007), Prensky (2013), Lorenzato (2012) y Pimenta (1997), fue realizado a partir del taller titulado "El Scratch potenciando el aprendizaje", desarrollada por los Laboratorio de Enseñanza de Matemáticas y Física (LEMAFI), de la Universidad Federal de Rio Grande - FURG, ofrecida para estudiantes del segundo semestre de Matemática Licenciatura de esta universidad. El estudio mostró que el uso del Scratch

\footnotetext{
1 Mestrando em Engenharia de Computação; Universidade Federal do Rio Grande - Furg; Rio Grande, Rio Grande do Sul, Brasil; Richard_n_machado@hotmail.com

2 Doutora em Educação em Ciências; Prefeitura Municipal do Rio Grande; Rio Grande, Rio Grande do Sul, Brasil; vandaead@gmail.com

3 Graduanda em Engenharia de Automação; Universidade Federal do Rio Grande - Furg; Rio Grande, Rio Grande do Sul, Brasil; mariana.obiedo@gmail.com

${ }^{4}$ Graduanda em Matemática Licenciatura; Universidade Federal do Rio Grande - Furg; Rio Grande, Rio Grande do Sul, Brasil; renatinhatruquijo@gmail.com
} 
en la enseñanza de la Matemática contribuye además del aprendizaje de los conceptos, con una programación de forma simple los estudiantes pasan por situaciones diferenciadas, en la introducción de situaciones abiertas y sugestivas para que busquen sus propias respuestas, a partir de sus conocimientos previos y los (re) elaborando, actividades que eleva la autoestima, los hace creativos y reflexivos y desarrolla las habilidades para el trabajo en equipo, con respecto al otro.

Palabras claves: Scratch, Taller pedagógico, Matemáticas, Programación, Situación problemática.

\begin{abstract}
This work aims to reflect about how to use Digital Technologies in the classroom to enhance teaching and learning. This is a study that moved the group upset them about what the teacher's role would be in the face of this reality. Thus, a qualitative analysis of a classroom workshop was carried out, highlighting its technical and pedagogical usability of Scratch software. The research, based on the theoretical perspective of Moran (2013), Papert (2007), Prensky (2013), Lorenzato (2012) and Pimenta (1997) was carried out from the workshop titled "The Scratch potentializing the learning", developed by members of the Laboratory of Mathematics and Physics Teaching (LEMAFI), Federal University of Rio Grande - FURG, offered to students of the second semester of Mathematics Degree of this university. The study showed that the use of Scratch in the teaching of Mathematics contributes beyond the learning of the concepts, with a simple program of programming the students pass through different situations, in the introduction of open and suggestive situations so that they look for their own answers, from their previous knowledge and (re)working out, activities that elevates self-esteem, makes them creative and reflective, and develops the skills for teamwork with respect to the other.
\end{abstract}

Keywords: Scratch, Pedagogical Workshop, Mathematics, Programming, Problem situation.

\title{
1. Introdução
}

Atualmente, os computadores e smartphones estão se tornando, praticamente, indispensáveis à atividade humana devido a transmissão rápida e democrática de informações. Segundo Prensky (2001) nossos alunos mudaram e não foi apenas o estilo de vestir e falar; para o autor ocorreram mudanças que não há volta: a chegada e rápida difusão das tecnologias digitais. E o resultado disso é que "os alunos de hoje pensam e processam as informações bem diferentes das gerações anteriores. Estas diferenças vão mais longe e mais intensamente do que muitos educadores suspeitam ou percebem" (PRENSKY, 2001, p.01).

A escola, atualmente, está vivenciando um desafio, o de incorporar a tecnologia digital nas atividades pedagógicas a fim de desenvolver outras formas de ensinar e aprender. Como pesquisadores nos questionamos: Como utilizar as Tecnologias Digitais na sala de aula para potencializar o ensinar e o aprender? Qual seria o papel do professor diante desta nova realidade? Pesquisas (BORBA, SILVA, GADANIDIS, 2015; LAURINO, SILVEIRA, 2016; SILVA, GAUTERIO, 2017; MACHADO; GAUTÉRIO, 2018) apontam caminhos interessantes para a associação das Tecnologias Digitais (TD) com as atividades escolares, no entanto, lançam um alerta para que estejamos atentos ao uso da TD para potencializar o processo de construção do conhecimento. Sendo assim, entendemos que não podemos utilizar 
as TD sem ter, anteriormente, realizado uma reflexão sobre os objetivos da atividade, a metodologia de ensino mais apropriada e ainda atentar à escolha dos softwares a serem utilizados. Como exemplo, para uma metodologia de ensino construtivista, é adequado selecionar um software que permita a construção de ambientes de simulação e jogos, como o Scratch. Este, é um ambiente de autoria que possibilita, tanto ao professor como ao aluno, a criação do seu próprio objeto de aprendizagem ou para o seu lazer, e que serve de embasamento para a compreensão de como ambientes pertencentes às TD se relacionam com a matemática e outras diversas áreas do conhecimento.

Com isso, este trabalho se encontra dividido em três seções sendo eles a Introdução, no segundo o Referencial Teórico utilizado para o desenvolvimento da proposta, no terceiro capítulo as potencialidades que o software Scratch possui e como pode ser empregado na educação e por fim seguem as considerações finais, no qual apontamos que o uso do Scratch, com sua programação de forma simples, os estudantes perpassam por situações inesperadas os fazendo a (re)pensar as estratégias, buscar conhecimentos prévios e (re)elaborar sua programação, situação que, no ensino da Matemática, contribui para além da aprendizagem dos conceitos, elevam a autoestima, os tornam criativos e reflexivos e desenvolvem habilidades para o trabalho em equipe, com respeito ao outro.

\section{Referencial Teórico}

O desenvolvimento, em ritmo acelerado, das Tecnologias da Informação e Comunicação (TIC) têm nos levado a diversas discussões, com destaque para a que permeia a comunidade escolar: Deve-se usar os computadores e smartphones no espaço escolar? De acordo com os Parâmetros Curriculares Nacionais - PCN (2000), parte II, que trata da Linguagens, Códigos e suas Tecnologias, "as novas tecnologias da comunicação e da informação permeiam o cotidiano, independente do espaço físico, e criam necessidades de vida e convivência que precisam ser analisadas no espaço escolar" (PCN, 2000, p. 11). Se voltarmos um pouco no tempo, com a popularização da televisão e do rádio, as pessoas se aproximaram das imagens, dos sons e até mesmo de espaços antes inimagináveis. As informações passaram a ser divulgadas de forma rápida, bem como a comunicação entre as pessoas, que passou a utilizar destes recursos. Quem nunca escutou um recado enviado pelo rádio? Nas regiões interioranas esta forma de comunicação ainda é utilizada. Lévy (2008) ainda vai além, compara o impacto das mídias com o surgimento da escrita, onde aprender, ensinar, informar-se e informar foram redefinidos. 


\subsection{O uso da Tecnologia Digital na Educação}

A tecnologia envolve conhecimento técnico e científico, podendo ser de fácil uso e rápida adequação ao ambiente escolar. Pode-se destacar como contribuições a facilidade de inserção para explanação e exploração dos assuntos abordados, facilitando para os estudantes a compreensão dos conceitos estudados. Na concepção de Pablos (2006), as tecnologias digitais podem desempenhar um papel inovador na medida em que potencializam outros formatos educativos. Segundo o autor, as Tecnologias da Informação e Comunicação rompem as barreiras limitadoras das disciplinas curriculares e permitem aos estudantes ampliar as possibilidades de construção de conhecimento devido ao contato com a multiculturalidade.

Atualmente, com a queda do valor econômico dos smartphones, ocorreu o aumento do número de pessoas que adquirem os aparelhos móveis e aprendem a usá-los, incluindo aquelas que vivem em vulnerabilidade social e econômica. Deste modo, as tecnologias móveis estão se tornando comuns até mesmo em áreas onde escolas, livros e computadores são escassos (UNESCO, 2014). Fato que favorece a educação, os aplicativos de aprendizagem móvel permitem às pessoas escolherem entre lições que exigem apenas alguns minutos e lições que requerem concentração por algumas horas. Essa flexibilidade permite que os estudantes se dediquem a suas atividades durante um intervalo longo, ou durante uma viagem curta de ônibus.

Jenkins et al. (2009) corroboram ao colocar que a escola deve contribuir para que os estudantes desenvolvam habilidades para lidar e interpretar as mídias digitais. Sabemos que, atualmente, estamos lidando com alunos Nativos Digitais (PRENSKY, 2001). No entanto, estes vêm construindo habilidades e competências por meio da interação com as TD, porém não percebendo o quanto estas tecnologias potencializam seu aprendizado. Talvez, esta desvalorização seja devido à pouca utilização dessas ferramentas no âmbito educacional. Para Jenkins et al. (2009) as TD têm o potencial de desenvolver habilidades importantes para os estudantes como: a capacidade de avaliar a confiabilidade e a credibilidade das fontes de informação, que achamos de extrema relevância; a capacidade de experimentar algumas ferramentas com o intuito de utilizá-lo para a resolução de problemas; a capacidade de improvisação, descoberta, interpretação, construir modelos ; e ainda, a capacidade dialogar de forma crítica com os pares sobre suas produções e conclusões pessoais e a (re)elaborar se for necessário.

Pesquisas (CRIVELLARO, NETO, RAXCHE (2001); HERNÁNDEZ (1998); FAGUNDES, SATO, LAURINO (1999); GALIAZZI; GARCIA, LINDEMANN (2004)) 
mostram temos diversas opções metodológicas como Ensino por Projetos, Projetos de Aprendizagem, Unidades de Aprendizagem, entre outras. Casal (2013, p. 6617) vai além, as definem como estratégias construtivistas alicerçadas na tecnologia, o que chama de “construtivismo tecnológico". Nas atividades alicerçadas nestas metodologias educativas, os estudantes são ativos e os professores possuem o papel de mediadores. São eficazes no trabalho com os alunos tanto da modalidade presencial e quanto a distância, e ainda nos possibilita avaliá-los de forma processual.

Segundo Moran (2013, p. 49) “a internet favorece a construção colaborativa, o trabalho conjunto entre professores e alunos, próximos física ou virtualmente". Devido a esse conjunto de opções, os professores discutem sobre o melhor modo de ensinar conhecimentos em sala de aula. A tecnologias podem servir-nos como apoio para um maior intercâmbio, trocas pessoais, em situações presenciais ou virtuais. Para Moran (2012), a tecnologia é um grande apoio de um projeto pedagógico que foca a aprendizagem ligada à vida. É um apoio que estabelece relações de parceria na aprendizagem.

Dessa forma, a possibilidade de uso das TD, principalmente com a presença dos smartphones, facilitou acolher as demandas provenientes das áreas de ensino e de aprendizagem, ampliando as possibilidades de compreensão de conteúdos e tornando mais concreta a aprendizagem. Também, podemos contar com os softwares característicos para a área educacional, incluindo novos métodos para o processo de ensino e aprendizagem.

\subsection{O Pensamento Computacional}

O Pensamento Computacional é uma abordagem de ensino que utiliza as mesmas técnicas da Ciência da Computação e está ampliando as possibilidades de inserção da TD na educação. O pensamento computacional já era utilizado na década de 60 pelo educador Seymour Papert, o qual já pensava que a tecnologia seria uma ferramenta auxiliar para o ensino e aprendizagem. Souza (2010) em uma entrevista com Papert, relata que ele é um dos maiores visionários do emprego da tecnologia vinculada a educação, só que na década em que realizou seus estudos as teorias em que desenvolveu pareciam ficção científica.

Segundo Gregolin (2001) o educador Seymour Papert, ao criar a linguagem LOGO, tinha como principal objetivo possibilitar o uso da tecnologia, disponível em sua época, para a educação. "O papel que atribuo ao computador é o de um portador de germes ou sementes culturais cujos produtos intelectuais não precisarão de apoio tecnológico uma vez enraizados numa mente que cresce ativamente." (PAPERT, 1980, p.23). 
O termo "Pensamento Computacional" foi apontado e teve grande repercussão por Jeannette Wing (2006) que publicou um artigo sobre o tema na revista Association for Computing Machinery (ACM). No entanto, percebemos que o artigo "Twenty things to do with a computer" (PAPERT, SOLOMON, 1972), já traz a ideia do Pensamento Computacional, porém os autores não o denominaram desta forma. Somente em 1980 Papert, em seu livro intitulado "Mindstorms: Children, Computers, 26 And Powerful Ideas" (PAPERT, 1980, p. 182), passou a utilizar-se do termo "Pensamento Computacional" em sua literatura quando se referia ao desenvolvimento cognitivo envolvido na formulação de um problema ou na busca pela sua solução, ou seja, ao algoritmo, de forma que um computador possa compreender.

Destacamos que o Pensamento Computacional não pode ser confundido com a simples aptidão de manusear aplicativos ou realizar tarefas de forma mecânica, limitando a criatividade da mente humana. Para Wing (2006), o Pensamento Computacional é uma habilidade que qualquer pessoa pode alcançar, não sendo necessária uma formação de técnica como cientista da Computação para desenvolvê-lo. A autora salienta que deveríamos adicionar Pensamento Computacional na capacidade analítica das crianças, uma vez que tal competência auxilia na abstração e decomposição de qualquer tarefa.

\subsection{O Scratch nas aulas de matemática}

O Scratch, sendo um software de linguagem gráfica de programação, desenvolvido com fins educacionais e em consonância com as ideias construtivistas de Papert (1994), é uma ferramenta gratuita e é considerada de fácil usabilidade. Tal característica se dá pelo fato de possuir uma IDE (do inglês Integreted Develpment Environment) a qual integra as várias ferramentas necessárias para o desenvolvimento das atividades, não precisando instalar arquivos complementares ou até mesmo digitar funções ou endereços, pois é uma linguagem de programação visual. Mélo (2011) considera o Scratch uma ferramenta que auxilia o ensino de conceitos de Lógica de Programação por possuir uma interface visual amigável e simples levando, de forma intuitiva, as principais estruturas de uma linguagem como: variáveis, operadores, estruturas de tomada de decisão e de repetição, e outros.

O software, além de potencializar a introdução da programação na educação, proporciona ao estudante a resolução situações problema que envolvem a matemática (por exemplo geometria plana e espacial). Segundo Prensky (2013), uma das maneiras mais acertadas de resolver problemas em Matemática é por meio da tecnologia. Contudo, ao planejar as atividades, deve-se ter objetivos pré-estabelecidos para buscar programas que 
levem os estudantes a pensar sobre as diferentes formas de estruturar o problema e como realizar os cálculos, possibilitando aos alunos a programar e a construir conhecimento sobre os conceitos matemáticos. São momentos que os estudantes, e até mesmo professor/mediador, passam a ser desafiados, desenvolvendo o pensamento criativo, o raciocínio sistemático e o trabalho colaborativo (PEREIRA, 2012).

Thompson e Lamshed (2006) ressaltam que o crescimento de ferramentas gratuitas e livres, como Scratch, contribuem para que os professores criem seus próprios materiais educacionais, mais adequados ao contexto escolar.

Com a facilidade de acesso aos smartphones e tablets, atualmente contamos com o aplicativo Scratch $\mathrm{Jr}^{5}$, desenvolvido a partir do Scratch, devido a necessidade do ensino de programação para crianças que estão ainda no jardim de infância (FLANNERY et al., 2013). $\mathrm{O}$ aplicativo disponibiliza recursos que viabilizam a utilização por crianças, como juntar os blocos de programação gráfica para fazer os personagens se moverem, pularem, dançarem e cantarem. Também é possivel modificar os personagens no editor de pintura, adicionar suas próprias vozes e sons, até mesmo inserir fotos de si mesmos.

Com o Scratch Jr, mesmo que ainda não estejam alfabetizadas, elas podem criar suas histórias programáveis enquanto desenvolvem habilidades de resolução de problemas, letramento, matemática e reforçam habilidades cognitivas e sociais.

Segundo Maturana (2006), devido ao caráter conservador de todo sistema social, a inovação é, ao menos inicialmente, resistida. Como toda sociedade efetiva-se devido à conduta dos sujeitos que a compõem, esta transforma-se somente se houver mudança de conduta de seus membros. Para Maturana e Varela (2005), na discussão com os colegas e os professores, os estudantes reformularam ou recriaram as observações, de forma que o grupo passa a aceitá-las e validando-as como explicações. Assim, como educadores, precisamos refletir sobre as diferentes formas de aprender, com o encadeamento da ação e da experiência, os estudantes, normalmente, validaram o conhecimento de uma forma particular.

\subsection{A formação de professores para o uso das TIC}

As Tecnologias da Informação e Comunicação (TIC) têm promovido mudanças estruturais e comportamentais que influenciam os meios educacionais e segmentos sociais,

\footnotetext{
${ }^{5}$ O ScratchJr é uma colaboração entre o grupo Developmental Technologies da Tufts University, o grupo Lifelong Kindergarten do MIT Media Lab e a Playful Invention Company. Dois Sigma liderou a implementação da versão Android do ScratchJr. Os gráficos e ilustrações do ScratchJr foram criados pela HvingtQuatre Company e pela Sarah Thomson.
} 
culturais e econômicos. A educação se depara com novos desafios diante da presença e automatização do uso das TD em todos os contextos, inclusive na escola. Tal cenário nos move a repensar o papel desta instituição.

As apropriações efetivas de conhecimentos tecnológicos, neste momento, não são apenas como procedimentos técnicos, mas ações que possibilitam a discussão e a reflexão dos saberes em construção, num movimento contínuo de conhecimento e autoconhecimento sobre o que se ensina e se aprende, transformando o fazer pedagógico. Isto reflete diretamente na educação, possibilitando romper com a transmissão de informações e a instrumentalização do conhecimento (VALENTE, 1999), e percebendo as Tecnologias da Informação e Comunicação como instrumento capaz de provocar o planejamento e a organização do ensino (ZAMPERETTI, 2016).

Pesquisas em Educação (BORBA, SILVA, GADANIDIS, 2015; D’AMBRÓSIO, 2007), principalmente em Educação Matemática, tem apresentado crescimento notável, o que contribui para o conhecimento dos processos que envolvem a construção de significados e conceitos, métodos de aprendizado e procedimentos de ensino. Assim, tais pesquisas devem refletir nos espaços escolares, no sentido de produzir reformulações curriculares e promover outros olhares para os saberes pedagógicos. A sociedade que hora se constitui - "uma sociedade aprendente" (GALLO; PINTO, 2010, p.01) - requer que a aprendizagem trilhe caminhos que articule saberes tanto presencial quanto a distância de modo contínuo.

Para D’Ambrósio (1994) a educação é uma ação engrandecedora para todos os sujeitos envolvidos, e faz-se necessário (re)conhecer saberes vinculados à realidade destes sujeitos e (re)construir conhecimentos, avançando coletivamente e contrapondo a ideia de trabalhar com conceitos extrínsecos àqueles contextos sociais. Lorenzato (2012) corrobora ao destacar que a mediação do professor e o uso que este faz dos meios que dispõe para potencializar o aprender é fundamental para que a aprendizagem dos alunos seja significativa. Assim, nos cursos de licenciatura, precisamos que sejam discutidas atividades pautadas em diferentes materiais didáticos-metodológicos e recursos tecnológicos que o discente possa ser instigado a refletir positivamente no planejamento e execução das aulas (LORENZATO, 2012). Isto se aplica a todas as áreas do conhecimento; neste artigo especificamente abordaremos na Educação Matemática.

Estudos (MISKULIN, 2012; LORENZATO, 2012; SCHEFFER, 2012) apresentam a importância de inserirmos a tecnologia na Educação Matemática. Esta, assume cada vez mais um papel fundamental na construção, geração e disseminação do conhecimento, ultrapassando a perspectiva de tecnologia voltada para o uso apenas como mais um recurso. A universidade 
é um espaço importante para esta inserção. Segundo o Projeto Político Pedagógico (2014) do curso de licenciatura em Matemática da FURG, desde o primeiro semestre, a estrutura curricular do curso prevê o uso de tecnologias para o ensino e aprendizagem. Assim, o discente contato com softwares específicos, preferencialmente os livres, com o intuito de desenvolver competências e habilidades para compreender, criticar e utilizar novas ideias e tecnologias para a resolução de problemas. E ainda, estabelecer relações entre a Matemática e outras áreas do conhecimento.

Para Pimenta (1997), os saberes docentes se (re)constroem a partir de suas atividades cotidianas e dos valores que o constitui, assim como das redes de conversações que estabelece com outros professores. A autora afirma que a construção da identidade do professor perpassa pelo saber da experiência, que está diretamente ligada às suas vivências enquanto aluno, e às percepções que têm daqueles educadores que foram significativos (ou não) em sua vida; perpassa também pelo saber do conhecimento, que é aquele produzido nos cursos de licenciatura, e ainda o saber pedagógico que implica em o que fazer com aquilo que se sabe.

Desta forma, entende-se que o professor em formação inicial precisa vivenciar práticas que auxilie sua aprendizagem "de forma mais integral, humana, afetiva e ética, integrando o individual e o social, nos diversos ritmos, métodos e tecnologias, a fim de construir cidadãos plenos em todas as dimensões" (GALLO; PINTO, 2010, p.01).

Sendo assim, é importante que as universidades passem a refletir sobre seus cursos e a formação continuada dos profissionais da educação, e também, divulgar atividades realizadas de modo a incentivar os professores da Educação Básica à busca pela renovação de suas práticas pedagógicas. Tais publicações podem servir de embasamento para outros profissionais durante o processo de composição seu material didático-metodológico e recursos tecnológicos para a sala de aula. No entanto, é sabido que os professores, tanto do meio universitário quanto da Educação Básica fazem, e muito, no decorrer de suas aulas. Porém, não existe a cultura de escrever sobre estes feitos, desvalorizando o objeto construído em sala de aula. Para Tardif (2010) “[...] o saber profissional se dá na confluência de vários saberes oriundos da sociedade, da instituição escolar, dos outros atores educacionais, das universidades, etc.” (p. 19). É preciso socializar nossas experiências, e, tal atitude, além de enobrecer o trabalho pedagógico dos professores, contribui para o desenvolvimento das atividades de seus pares.

Assim, esta é uma oficina desenvolvida por integrantes do Laboratório de Educação Matemática e Física (LEMAFI) da Universidade Federal do Rio Grande - FURG em parceria com a Secretaria Municipal de Educação, do município de Rio Grande, que foi oferecida a 
discentes de Matemática em Licenciatura Plena, da mesma universidade. Têm como objetivo a (re)construção conhecimento com ênfase na ação, sem perder de vista a base teórica, e assumindo a ideia de que os professores/estudantes são sujeitos ativos e aprendentes em constante processo de transformação na convivência com o outro. Além disso, propõe uma reflexão sobre como utilizar as Tecnologias Digitais na sala de aula para potencializar o ensinar, o aprender, e qual seria o papel do professor diante desta nova realidade.

\section{3 . Desenvolvimento: A oficina em ação}

Nesta seção, é apresentado o relato da experiência vivenciada durante a oficina oferecida para 36 acadêmicos do segundo semestre do curso de Licenciatura em Matemática, na disciplina denominada Tecnologias Aplicadas à Educação Matemática I.

Ao realizar um estudo teórico acerca da formação inicial e continuada dos professores, investigando como utilizar as Tecnologias Digitais na sala de aula para potencializar o ensinar e o aprender, e qual seria o papel do professor neste ambiente. Foi possível perceber diversos conceitos matemáticos a serem explorados por meio do Scratch, e indicar possíveis atividades práticas a serem desenvolvidas para uma sala de aula de Matemática.

Diante desta realidade, para posteriormente realizar uma análise qualitativa da oficina, foram levantados dados a partir do registro feito no fórum de discussão no Ambiente Virtual de Aprendizagem (AVA) da disciplina e das anotações feitas no diário dos pesquisadores. Segundo Behar e Leite (2005):

[...] a expressão Ambiente Virtual de Aprendizagem (AVA) é entendida como um espaço na Internet formado pelos sujeitos, suas interações e as formas de comunicação que se estabelecem através de uma plataforma de software (infraestrutura tecnológica composta pelas funcionalidades e interface gráfica), tendo como foco principal a aprendizagem. $(2005$, p.2)

Na FURG, o AVA utilizado é o Modular Object Oriented-Dynamic Environment (Moodle) desenvolvido por Dougiamas (2001). Neste espaço, os professores gerenciam as disciplinas postando o material didático e as tarefas complementares, que são realizadas online, de forma síncrona e/ou assíncrona.

O consenso entre a teoria e a prática na formação de professores é emergente para a promoção de um diálogo reflexivo e, compreender essas práticas é fundamental no sentido de trazer para a discussão novas perspectivas de educação. Assim, este trabalho está alicerçado na abordagem qualitativa, a qual permite que os pesquisadores tenham a liberdade de investigar, valorizar e aprender os fenômenos pesquisados, entendendo as ocorrências da pesquisa e o contexto na qual as informações foram colocadas. Segundo Minayo (1994), esta 
metodologia "responde a questões muito particulares" e "trabalha com o universo de significados, motivos, aspirações, crenças, valores e atitudes, o que corresponde a um espaço mais profundo das relações" (MINAYO, 1994, p. 21-22).

\subsection{O Scratch potencializando o aprender}

Nesta oficina, trabalhou-se para além das estruturas e funcionamento dos processos reais de ensino e aprendizagem, mas também no estudo das possibilidades de estruturação e funcionamento de novas possibilidades (PIMENTA, 1997).

Durante a organização da oficina foram selecionados alguns artigos para a leitura prévia, os quais foram disponibilizados pela professora responsável pela disciplina no AVA. Dentre os textos discutidos estão: "Utilização do Scratch em sala de aula" (SÁPIRAS, VECCHIA, MALTEMPI, 2015); "A Construção de Jogos Eletrônicos e a Modelagem Matemática na Realidade do Mundo Cibernético" (VECCHIA, MALTEMPI, WEINGARTEN, 2013); e "Programando com o Scratch na aula de matemática" (ROCHA, 2015).

No primeiro texto Sápiras, Vecchia, Maltempi (2015) trazem uma análise qualitativa de uma experiência com estudantes, dos anos finais do Ensino Fundamental, de uma escola do Sul do Brasil buscando indícios da formação de habilidades relacionadas à literacia digital e sua associação com aspectos lógicos matemáticos na construção de jogos utilizando o software Scratch. O estudo mostrou que tanto a matemática quanto aspectos computacionais podem fomentar a construção da habilidade chamada de simulação.

No texto seguinte, Vecchia, Maltempi, Weingarten (2013) salientam as potencialidades do processo de construção de jogos eletrônicos por meio do Scratch, dinâmico e não-linear, para com os processos de ensino e aprendizagem da matemática e a sua relação com a Modelagem Matemática. O público alvo esta pesquisa foram os discentes do curso de Licenciatura de Matemática, de uma universidade do Sul do Brasil. A pesquisa mostrou que o modelo é expresso por uma linguagem específica que, embora tenha uma sustentação baseada na lógica proposicional, pode também apresentar a matemática utilizada no contexto escolar e acadêmico de modo explícito. Sendo assim, construção de jogos eletrônicos utilizando o Scratch potencializa o processo de ensino e aprendizagem da matemática, quando abordado sobre a ótica da Modelagem Matemática e ainda, pode contribuir para desmistificar a ideia de que o computador gera resultados que garantem certeza. 
No texto "Programando com o Scratch na aula de matemática" a autora apresenta um estudo de caso, que visava contribuir para desenvolvimento de atividades envolvendo programação que favorecessem a construção de conceitos matemáticos, com alunos do Ensino Fundamental, no Sul do Brasil, que construíram o conceito de ângulo via programação de labirintos utilizando o software Scratch. Rocha (2015) concluiu que as atividades foram significativas, permitindo a utilização de diferentes esquemas resultantes de suas experimentações dentro e fora da escola. O estudo de caso permitiu um olhar mais aguçado para a programação, em especial o Scratch, uma ferramenta que pode contribuir para o processo de ensino aprendizagem da Matemática.

No primeiro momento da oficina, foi realizada uma roda de conversa discutindo compreensões a respeito os textos, as aproximações entre as experiências relatadas, 0 embasamento teórico que cada autor(a) utilizou e as aproximações com os teóricos que foram estudados no curso até o momento. Ainda, foi discutida a possibilidade de realizar alguma atividade semelhante no contexto em que os discentes presentes estão incluídos.

Durante o diálogo, um dos estudantes relatou: "tenho medo de usar tal ferramenta, uma vez que as crianças abstraem a teoria matemática exposta em sala de aula e apenas se concentram em vencer o desafio proposto no jogo." (Discente 3). Percebe-se que discentes do curso de Matemática, assim como muitos professores da Educação Básica, não identificam os jogos e softwares como ferramentas aliadas ao ensino, e que instigam os estudantes a explorar novos conceitos de forma contextualizada, criando hipóteses e auxiliando a estabelecer relações entre a situação problema e a situação vivenciada através da tecnologia digital. Gallo e Pinto (2010, p. 3) esclarece-nos que, estes Objetos podem "possibilitar ao aluno testar diferentes caminhos, acompanhar a evolução temporal das relações, verificar causa e efeito, criar e comprovar hipóteses, relacionar conceitos, despertar a curiosidade e resolver problemas, de forma atrativa e divertida, como uma brincadeira ou jogo".

Após, foi apresentado o jogo "Desafios na Floresta", desenvolvido no Scratch pelos componentes do LEMAFI. Através do jogo, foi ilustrada uma alternativa de como o educador pode compor um jogo de labirinto, explorando caminhos com geometrias específicas, e também como o processo de criação do jogo demanda uma análise dos casos a serem estudados. Finalmente, foi apresentada a linguagem de programação Scratch, dando enfoque aos blocos com função de "laços de repetição" e "funções lógicas". De modo prático, foi apresentado como compor um código para para mover o personagem no plano cartesiano. 
constitui numa atividade de reflexão que enriquece a teoria que lhe deu suporte. $\mathrm{O}$ estágio é um processo criador, de investigação, explicação, interpretação e intervenção na realidade (PIMENTA, 1995, p. 74).

Ao longo da oficina, os estudantes foram desafiados a criar um projeto utilizando o Scratch para compor seu planejamento de aula em um estágio de docência. Durante esta atividade, os integrantes do LEMAFI puderam dialogar com os estudantes, instigando-os a refletir sobre quais os conceitos matemáticos estariam envolvidos no projeto. Ainda, foi oferecido aos estudantes suporte a respeito de lógica de programação, visto que, inicialmente, foi apresentada uma resistência quanto a composição dos algoritmos. Tal efeito ocorreu, pois os estudantes apresentam uma distância significativa de atividades envolvendo lógica, e, por consequência, do Pensamento Computacional. Contudo, acredita-se que esta barreira pode ser eliminada ao disponibilizar um breve Tutorial do Scratch, envolvendo conceitos básicos e situações chave a serem resolvidas em grupos de trabalho.

Foi percebido, através dos relatos dos estudantes, que em um primeiro momento utilizar este software foi, de fato, uma tarefa complexa à falta de experiência. Todavia, após o primeiro contato, formaram-se espontaneamente alguns grupos de trabalho, onde os estudantes puderam discutir sobre o funcionamento da ferramenta, tornando a atividade divertida e prazerosa. Em um dos relatos o estudante informou: “[...]fiquei meio perdido no começo, mas logo comecei a interagir e achei fácil de usar, bastante prático e divertido. Após aprender alguns comandos conseguiria fazer até mais algum projeto.” (Discente 15). Segundo Kenski (2008), não bastam avançados equipamentos disponíveis, a boa vontade ou a submissão dos professores às instruções dos técnicos ou breves cursos; é preciso que os professores se sintam confortáveis para utilizar esses auxiliares didáticos.

De início achei bastante complicado, mas conforme fui usando vi que não é nenhum bicho de sete cabeças, as ferramentas para construção são bem fáceis de usar. A ajuda dos que estavam ministrando a oficina foi indispensável para que pudesse elaborar minha animação e conhecer melhor as utilizações do Scratch. Oficinas sempre são muito agregadoras, o relato de experiências obtidas pelos professores ajuda muito na nossa construção enquanto docentes. Gostei muito do software ele tem inúmeras formas possíveis de se trabalhar o conteúdo de matemática com os alunos em forma de animações, de perguntas e respostas entre outras, basta apenas que se tenha um pouco mais de experiência com o mesmo para construir coisas incríveis para as crianças." (Discente 31).

O aplicativo Scratch na minha opinião é um software foi muito interessante, pois nele os alunos utilizam a matemática implicitamente, eles aprendem na base da tentativa e erro, usam algoritmos com visualização de blocos, o que deixou o programa mais suave. A partir da minha pouca experiência com o Scratch eu pude perceber que o aplicativo é de suma importância para a aprendizagem, pois nele podemos fazer diversas animações usando a matemática e a imaginação. (Discente 8). 
Através do relato dos Discentes, percebe-se que o Scratch é uma ferramenta que beneficia a aprendizagem. Logo, é possível que os estudantes aprendam a matemática de uma maneira diferente da tradicional. Utilizando esta ferramenta nas salas de aula, é possível compor atividades lúdicas e interativas.

Eu vi o software como um grande aliado no intuito de chamar a atenção dos alunos, principalmente na matemática onde existem muitos mitos. Através dele, podemos abordar, ensinar e brincar com diversos conteúdos, e o principal, não só de matemática, mas misturando outras matérias, tirando esse paradigma de que matemática é difícil e sim, mostrando que tem matemática em tudo, e que é fácil. (Discente 22).

O discurso do Discente 22 corrobora com as ideias de Papert (2007) quando destaca que o conhecimento científico é trabalhado em minúsculos pedaços, o que pode-se fazer é memorizá-lo na aula e reproduzi-lo no momento da avaliação. Se estivesse integrado num contexto de uso, se aproveitaria seu potencial de formação de conceito pela prática, formando a corrente experiencial e progressiva. Sendo assim, é importante buscar inovações sistêmicas e baseadas no experimentalismo, alterando o modelo de prática docente e curricular.

\section{Considerações}

As transformações de nossa atual sociedade e as discussões apontadas pelos avanços tecnológicos mostram a necessidade de uma reestruturação da prática de ensino, a ser implementada por uma reflexão crítica sobre o trabalho do professor em sala de aula e o uso das TD. No entanto, como utilizar as Tecnologias Digitais na sala de aula para potencializar o ensinar? O estudo mostrou que utilizar um recurso tecnológico para a aprendizagem não é tarefa fácil, temos que aliar a tecnologia a uma metodologia construtivista, mas o estudo mostra que é uma experiência motivadora.

Os discentes do curso de licenciatura em Matemática, após a leitura e discussão dos textos sugeridos, reconheceram a importância do uso das tecnologias associado ao processo de ensino e aprendizagem. O uso das TD na escola, aliados a uma metodologia de ensino, é importante devido seu potencial para motivar o aluno à pesquisa e a autonomia para buscar novas aprendizagens e habilidades como, por exemplo, para o trabalho coletivo, forma cooperativa e colaborativa, assim a construção do conhecimento ocorre de forma divertida e inovadora.

Após a oficina intitulada "O Scratch potencializando o aprender" os discentes dos cursos de graduação colocaram que se sentem motivados em utilizar ferramentas tecnológicas. Com o Scratch, os estudantes passa de espectador para um ser ativo no seu 
próprio processo de aprendizagem, vivencia uma a aula de maior dinamicidade. Assim, o uso do Scratch no ensino da Matemática contribui para além da aprendizagem dos conceitos, com uma programação de forma simples os estudantes perpassam por situações diferenciadas, na introdução de situações abertas e sugestivas para que busquem suas próprias respostas, a partir de seus conhecimentos prévios e os (re)elaborando, atividades que eleva a autoestima, os tornando criativos e reflexivos e desenvolvendo o habilidades para o trabalho em equipe, respeitando um ao outro.

E qual seria o papel do professor diante desta nova realidade? Este não perderá seu espaço na sala de aula, se tornará o mediador. O professor se coloca entre o aluno e a aprendizagem deixa de ser o detentor de todo o saber, e passa a perceber que não basta responder, é necessário fazer boas perguntas, considerar as experiências do aluno, transcendendo a sala de aula. O conhecimento descentraliza-se e os dois, professor e aluno, aprendem juntos, de forma significativa.

\section{Referências}

BEHAR, P. A.; LEITE, S. M. Criando Novos Espaços Pedagógicos na Internet: O Ambiente ROODA. In: WWW/Internet, 2005, Lisboa. Anais do. Lisboa: IADIS. V.1. p. 3 - 10, 2005. Disponível em: Acesso em: 22 dez. 2018.

BORBA, M.C.; SILVA, R.S.R; GADANIDIS,G. Fases das Tecnologias Digitais em Educação Matemática. 1a Edição. Belo Horizonte: Autêntica, 2015.

BRASIL. Secretaria de Educação Média e Tecnológica. Parâmetros curriculares nacionais (Ensino Médio) - Linguagens, Códigos e suas Tecnologias. Brasília, 2000. Disponível em: Acesso em 04 jan. 2019.

CASAL, J. A. V. Construtivismo tecnológico para promoção de motivação e autonomia na aprendizagem. In: Atas do XII Congresso Internacional Galego-Português de Psicopedagogia. Braga: Universidade do Minho, 2013, p. 6616 - 6631.

CRIVELLARO, C. V.; NETO, M. R.; RACHE, R. P. Ondas que te quero mar: educação ambiental para comunidades costeiras - Mentalidade marítima: relato de uma experiência. Porto Alegre: Gestal/NEMA, 2001. Disponível em: $<$ http://www.remabrasil.org/Members/bosco/artigos/livro-ondas-que-te-quero-mar-educacaoambiental-para-comunidades-costeiras/>. Acesso em: 09 jan. 2019. 
D’AMBROSIO, U. Ação Pedagógica e Etnomatemática como Marcos Conceituais para o Ensino de Matemática. In: BICUDO, Maria Aparecida Viggiani (Org). Educação Matemática. São Paulo: Moraes, 1994.

D’AMBRÓSIO, U. Educação Matemática: da Teoria à Prática. Campina, SP: Papirus, 2007.

DOUGIAMAS, M. Moodle: open-source software for producing internet-based courses. 2001. Disponível em: < http://moodle.com/>. Acesso em: 25 dez. 2018.

FAGUNDES, L. C.; SATO, L.; LAURINO-MAÇADA, D. Aprendizes do futuro: as inovações começaram! Brasília. PROINFO/SEED/MEC, 1999.

FLANNERY, L. P. et al. Designing ScratchJr: Support for early childhood learning through computer programming. In: Proceedings of the 12th International Conference on Interaction Design and Children. ACM, 2013. p. 1-10.

GALIAZZI, M. C.; GARCIA, F. Á.; LINDEMANN, R. H. Construindo Caleidoscópios organizando unidades de aprendizagem. In: MORAES, R.; MANCUSO, R. Educação em Ciências - produção de currículos e formação de professores. Ijuí: Unijuí, 2004. p. 65-84.

GALLO, P.; PINTO, M. das G. Professor, esse é o objeto virtual de aprendizagem. Revista Tecnologias na Educação, ano 2, n.1, jul. 2010. Disponível em: <http://tecnologiasnaeducacao.pro.br/wp-content/uploads/2015/07/Art2-vol2-julho2010.pdf>. Acesso em: 05 fev. 2018.

GREGOLIN, V. R. Linguagem LOGO: Explorando Conceitos Matemáticos. UNESP Universidade Estadual Paulista. São Paulo: 2001. Disponível em: . Acesso: 02 jan 2019.

HERNÁNDEZ, F. Transgressão e Mudança na educação: Os Projetos de Trabalho. Porto Alegre, RS: ARTMED, 1998.

JENKINS, H. et al. Confronting the challenges of participatory culture: Media education for the 21st century. Chicago: The MacArthur Foundation, Mit Press, 2009.

KENSKI, Vani Moreira. Educação e Tecnologias: o novo ritmo da informação. Campinas: Papirus, 2008.

LAURINO, D. P.; SILVEIRA, D. S. (Orgs). Projeto Novos Talentos: experiências com tecnologias no ensinar e aprender matemática. Rio Grande: Pluscom, 2016. [edição eletrônica] 
LÉVY, P. As tecnologias da inteligência: o futuro do pensamento na era da informática. Trad. Carlos Irineu da Costa. Rio de Janeiro: ED. 34, 2008.

LORENZATO, S. O Laboratório de ensino de Matemática na formação de professores. Campinas: Editores Associados, 2012. In: LORENZATO, S. (Org). Laboratório de Ensino de Matemática na formação de professores. Campinas: Autores Associados, 2012. p.77- 92.

MACHADO, R. N. ; GAUTERIO, V. L. B. . O pensamento computacional na escola: o uso da robótica no ensino fundamental para potencializar as aprendizagens matemáticas. Redin Revista Educacional Interdisciplinar v. 7, n. 1 (2018).

MATURANA, H.; VARELA, F. A árvore do conhecimento: as bases biológicas do entendimento humano. São Paulo: Psy, 1995.

MATURANA, H.M. Cognição, ciência e vida cotidiana. Belo Horizonte: UFMG, 2006.

MÉLO, F. E. N., et. al. Do Scratch ao Arduino: Uma proposta para o ensino introdutório de programação para cursos superiores de tecnologia. XXXIX Congresso Brasileiro de Educação em Engenharia, Blumenau, SC, 2011. Disponível em Acesso em 10 de jan de 2019.

MINAYO, M. C. de S. (Org.). Pesquisa social: teoria método e criatividade. $17^{\mathrm{a}}$ ed. Petrópolis, RJ: Vozes, 1994. 80 p.

MISKULIN, R. G. S. As potencialidades didático-pedagógicas de um laboratório em educação matemática mediado pelas TICs na formação de professores. In: LORENZATO, S. (Org). Laboratório de Ensino de Matemática na formação de professores. Campinas: Autores Associados, 2012. p.153-178.

MORAN, J. M. A internet na educação. USP-2002. Entrevista, portal educacional, v. 2, 2012.

MORAN, J. M. Ensino e aprendizagem inovadores com tecnologias Audiovisuais e Telemáticas. In: MORAN, José Manuel (org) Novas Tecnologias e Mediação Pedagógica. Editora Papirus, $21^{\mathrm{a}}$ Ed, 2013.

PABLOS, J. A visão disciplinar no espaço das tecnologias da informação e comunicação. In. Sancho, J. M. et al. Tecnologias para transformar a educação. Porto Alegre: Artmed, 2006.p.63-85.

PAPERT, S. Mindstorms - Children, Computers and Powerful Ideas. New York: Basic Books, Inc, 1980. 
PAPERT, S.The Children's Machine: Rethinking School in the Age of the Computer. New York: Basic Books, 1994.

PAPERT, S. Logo, computadores e educação. São Paulo: Brasiliense, 1980.

PAPERT, S. A Máquina das Crianças: Repensando a Escola na Era da Informática. Porto Alegre: ArtMed, edição revisada, 2007.

PAPERT, S.; SOLOMON, C. Twenty things to to with a Computer. Educational Technology Magazine, 1972. Disponível em: http://www.stager.org/articles/twentythings.pdf. Acesso em 03 jan 2019.

PEREIRA, P. S.; et. al. Análise do Scratch como ferramenta de Auxílio ao Ensino de Programação de Computadores. Instituto Federal de Educação, Ciência e Tecnologia do Ceará, Fortaleza - CE, 2012. Disponível em . Acesso em 19 janeiro2013.

PIMENTA, S. G.. O estágio na formação de professores: unidade teoria e prática. $3^{\text {a }}$ ed. São Paulo: Cortez, 1997.

O pedagogo na Escola Pública. São Paulo: Edições Loyola, 1995.

PRENSKY, M. Digital Native, digital immmigrants. Digital Native immigrants. On the horizon, MCB University Press, Vol. 9, N.5, October, 2001. Disponível em: . Acesso em: 07 de jan. 2019.

PRENSKY, M. Our brains extended. Technology-RichLearning, v. 70, n. 6, 2013.

Projeto Político Pedagógico do curso de licenciatura em Matemática da FURG, 2014. Disponível https://imef.furg.br/images/stories/documentos/projeto_pedaggico_matemtica_licenciatura.pd f. Acesso em 02 jan 2019.

ROCHA, K. C. Programando com o scratch na aula de matemática. Renote. Revista novas tecnologias na educação , v. 13, p. 1-10, 2015. Disponível em https://seer.ufrgs.br/index.php/renote/article/view/61429. Acesso em 06 dez. 2018.

SÁPIRAS, F. S.; VECCHIA, D. R.; MALTEMPI, M. V. Utilização do Scratch em sala de aula. Educação Matemática Pesquisa: Revista do Programa de Estudos Pós-Graduados em Educação Matemática, [S.1.], v. 17, n. 5, p. 973 - 988, dez. 2015. ISSN 1983-3156. Disponível em: <https://revistas.pucsp.br/index.php/emp/article/view/25152>. Acesso em: 06 dez. 2018. 
SCHEFFER, N. F. O LEM na discussão de conceitos de geometria a partir de mídias: dobradura e software de dinâmico. LORENZATO, S. (org.). O laboratório de ensino de matemática na formação de professores. $3^{\mathrm{a}}$. ed. Campinas, SP: Autores Associados, 2012. p. 93-112.

SILVA, R. S; GAUTERIO, V. L. B. O potencial da produção de vídeo aulas de geometria. ARTFACTUM- Revista de estudos em Linguagens e Tecnologia, V. 14, n.1, 2017.

SOUZA, A. de F. Entrevista com Seymour Papert: A maior vantagem competitiva é a habilidade de aprender. Artigo publicado na Revista Super Interessante, 2010. Disponível em: $<$ http://www.dimap.ufrn.br/ jair/piu/artigos/seymour.html $>$. Acesso em: 4 jan de 2019

TARDIF, M. Saberes docentes e formação profissional. 11. ed. Petrópolis, RJ: Vozes, 2010.

THOMPSON, L.; LAMSHED, R. E-learning within the building and construction and allied trades. Flexible Learning Advisory Group, 2006.

UNESCO. Diretrizes de políticas da UNESCO para a Aprendizagem Móvel. Organização das Nações Unidas para a Educação, a Ciência e a Cultura. 2014. Disponível em: <http://unesdoc.unesco.org/images/0022/002277/227770por.pdf > Acesso em: 19 de ago de 2017.

VALENTE, J. A. Informática na educação. Revista Pátio, ano 3., n. 09. Porto Alegre, maio/jul, 1999.

VECCHIA, R. D.; MALTEMPI, M. V.; WEINGARTEN, T. A Construção de Jogos Eletrônicos e a Modelagem Matemática na Realidade do Mundo Cibernético. Educação Matemática em Revista-RS , v. 2, p. 48-57, 2013. Disponível em http://sbemrs.org/revista/index.php/2011_1/article/view/95. Acesso em 06 out. 2018.

WING, J. M. Computational thinking. Communications of the ACM, v. 49, n. 3, p. 33, 2006.

ZAMPERETTI, M. P.; ROSSI, F. D. Tecnologias e ensino de artes visuais - apontamentos iniciais da pesquisa. HOLOS, [S.1.], v. 8, p. 190-200, jan. 2016. ISSN 1807-1600. Disponível em: <http://www2.ifrn.edu.br/ojs/index.php/HOLOS/article/view/2031>. Acesso em: 14 jan. 2019. 